\title{
Association of PET Scan Parameters of Pulmonary Masses and Reticuloendothelial System with Hematologic Parameters
}

Halil Komek ${ }^{*}$, Serdar Altindag and Canan Can

Department of Nuclear Medicine, Saglik Bilimleri University Diyarbakir Gazi Yasargil Training and Research Hospital, Diyarbakir, Turkey

*Corresponding author: Halil Komek, Department of Nuclear Medicine, Saglik Bilimleri University Diyarbakir Gazi Yasargil Training and Research Hospital, Diyarbakir, Turkey. Tel: 904122580101; Fax: 90412 2580060; E-mail: halilkomek@gmail.com

Received date: January 14, 2017; Accepted date: February 08, 2017; Published date: February 13, 2017

Copyright: @ $2017 \mathrm{Komek} \mathrm{H}$, et al. This is an open-access article distributed under the terms of the Creative Commons Attribution License, which permits unrestricted use, distribution, and reproduction in any medium, provided the original author and source are credited.

\begin{abstract}
Objectives: The most active organs of the reticuloendothelial system (RES) are the liver, spleen and bone marrow, having immune mechanisms against malignancy including neutrophils and platelets. RES may be imaged by different modalities, like PET scan. Neutrophil lymphocyte ratio (NLR) and platelet lymphocyte ratio (PLR) have gained importance as proinflammatory markers in cancer, e.g. lung cancer. The aim of this study was to investigate the relationship between PET parameters of pulmonary mass or RES, and hematological parameters, and to evaluate the role of these factors in differentiating the pathological character of the mass.
\end{abstract}

Methods: A retrospective analysis of the data of 131 patients, retrieved from the department archives, with pulmonary mass limited to mediastinum was made. Patients were grouped according to pathological results: benign mass $(n=46)$, squamous cell carcinoma $(n=38)$, and non-squamous cancer of lung $(n=47)$. All patients underwent PET/CT scanning and images were analyzed retrospectively. Maximum and mean SUV were calculated from primary lesions and RES. NLR and PLR were calculated from CBC.

Results: SUV $V_{\max }$ and SUV mean of RES organs were similar for both groups with benign and malignant pulmonary masses, and among the subgroups. SUV $V_{\max }$ ratios of pulmonary mass were significantly different between the groups (the highest value in the squamous cell carcinoma and the lowest in the benign groups). No significant difference was determined between the subgroups for NLR and PLR. NLR was significantly correlated with SUV max $_{\text {m }}$ ratios of spleen and the mass, and SUV mean ratios of spleen and bone marrow. PLR was significantly correlated with $S U V_{\max }$ ratios of spleen, bone marrow, the mass and $S U V_{\text {mean }}$ ratios of spleen, bone marrow.

Conclusion: SUV of RES and primary mass were correlated with NLR and PLR, indicators of systemic inflammation. The associations between NLR and PLR, and SUV should be clearly defined by further investigations.

Keywords: Neutrophil lymphocyte ratio; Platelet lymphocyte ratio; SUV; Reticuloendothelial system

\section{Introduction}

The reticuloendothelial system (RES) was first described by Aschoff in 1924, and is also known as the monocyte macrophage system. The organs containing the most active reticuloendothelial cells are the liver, spleen and bone marrow. Monocyte-macrophage groups of cells residing in these organs play a role in inflammation and immunity, such as defense against pathogens, removal of dead cells, debris and malignant cells. The cells of this system are motile and phagocytic, so that they can ingest and destroy unwanted foreign material. They play important roles both in cellular and adaptive immunity, and in defense against tumors.

Fluorine-18-2-fluoro-2-deoxy-D-glucose (18F-FDG) positron emission tomography (PET) can be used to diagnose, to stage and monitor patients with different kinds of malignant tumors, and to detect recurrence in such patients. This modality has also been adopted as an effective method to diagnose and monitor several benign conditions, such as infectious and inflammatory processes. Therefore, as RES is one of the effectors of systemic immunity, 18F-FDG PET could have an important place in determining the existence and amount of immune response in RES organs against malignancy. Combined PET/CT screening provides metabolic information from PET and anatomical information from CT (computed tomography). Maximum standardized uptake value $\left(\mathrm{SUV}_{\max }\right)$ is one of the most frequently used parameters of PET/CT, reflecting metabolic activity of the tumor.

Some hematological parameters in addition to platelets, leukocytes, neutrophils and lymphocytes have gained importance in recent years, such as neutrophil lymphocyte ratio (NLR), and platelet lymphocyte ratio (PLR). NLR and PLR have been revealed as proinflammatory markers in some studies [1-3] and in cancer patients. Previous studies have shown that neutrophils and platelets have different actions in tumor immunology. A significant correlation has been determined between increased neutrophil counts and tumor aggressiveness. These parameters have been investigated in cardiovascular studies many times, but few studies have investigated the correlations between these parameters and PET SUV $\mathrm{SUx}_{\max }$ of tumoral masses and RES organs in cancer patients.

Lung cancer is known to be one of the major causes of cancerrelated death and 3 million new cases per year are reported worldwide. The overall 5 year survival rates of lung cancer increased to $15 \%[4,5]$. It is also known that lung cancer is the second most common cancer in 
both males and females. The most common type of lung cancer encountered in patients is adenocancer, followed by squamous cell carcinoma of the lung. As in other types of cancer, the immune system is activated in lung cancer against malignant cells. This activation may be reflected both in the blood as alterations in hematological parameters and in RES organs such as the liver, spleen and bone marrow. Although hematological alterations may be measured by counting, changes in RES can be shown by imaging modalities, such as 18F-FDG PET/CT determining metabolic activity.

The aim of this study was to investigate the relationship between $\mathrm{SUV}_{\max }$ in pulmonary mass limited to the mediastinum measured by PET scanning and hematological parameters, and to evaluate the importance of these values in the discrimination of pathological diagnosis of the mass as malignant or benign. It was also aimed to determine whether there was any association between PET/CT parameters reflecting RES activity and hematological parameters, and the value of these factors in differentiating the pathological character of the mass as benign or malignant.

\section{Materials and Methods}

Of the total 12,380 patients on whom PET/CT imaging was performed between June 2012 and June 2016, evaluation was made of 2256 patients who were referred with pre-diagnosis of mediastinal or pulmonary mass. Of these, 516 patients had no extra-thoracic involvement in PET/CT, so of these, 131 had pathological recordings and complete blood count in same week and were included in the study, while the others were excluded. The data of the patients admitted were analyzed retrospectively by retrieving the patient files from Department of Nuclear Medicine, Saglik Bilimleri University Diyarbakir Gazi Yasargil Training and Research Hospital, Diyarbakir, Turkey. The patients were grouped as benign mass $(n=46)$, squamous cell carcinoma of the lung $(n=38)$, and non-squamous cancer of the lung $(n=47)$, according to the pathological results of the examined biopsy or excised material.

The PET/CT images of the patients were analyzed again retrospectively. All patients underwent routine PET/CT scanning with Biograph 6 PET/CT (Siemens Medical Systems, CTI, Knoxville, TN, USA). Images were taken after at least 6 hours fasting, and glucose levels in peripheral blood in all patients were confirmed to be 140 $\mathrm{mg} / \mathrm{dl}$ or less before the FDG injection. Approximately $5.5 \mathrm{MBq} / \mathrm{kg}$ of FDG was administered intravenously 1 hour before image acquisition. After the initial low-dose CT (Discovery 600: Biograph 6: $40 \mathrm{~mA}, 120$ $\mathrm{kVp}$ ), standard PET imaging was performed from the skull base to the proximal thighs with an acquisition time of $3 \mathrm{~min} / \mathrm{bed}$ in threedimensional mode. Images were then reconstructed using the ordered subset expectation maximization algorithm (2 iterations, 20 subsets). $\mathrm{SUV}_{\max }$ values were calculated from primary lesions in the mediastinum or lung in all patients. Volume of interest (VOI) of $2 \mathrm{~cm}$ diameter was taken in the liver, spleen, abdominal aorta, and L2 vertebra, and thus $\mathrm{SUV}_{\max }$ and $\mathrm{SUV}_{\text {mean }}$ values were obtained. The
SUV values of the aorta and liver were accepted as reference values. $\mathrm{SUV}_{\max }$ ratios of liver/aorta, spleen/aorta, bone marrow/aorta, spleen/ liver, bone marrow/liver, and $\mathrm{SUV}_{\text {mean }}$ ratios of liver/aorta, spleen/ aorta, bone marrow/aorta, spleen/liver, bone marrow/liver were calculated, and RES activity in PET/CT was calculated. SUV $\mathrm{max}_{\max }$ ratios of mass/liver, mass/aorta were calculated and standardized in all patients.

In all patients, leukocyte, neutrophil, thrombocyte and lymphocyte counts were measured as the number of cells per microliter in complete blood count (CBC) analyzed by automatic hematology analyzer. NLR was calculated by dividing the neutrophil count by the lymphocyte count, and PLR by dividing the platelet count by the lymphocyte count.

SPSS 22.0 (IBM Corporation, Armonk, New York, United States) program was used for analysis of variables. The conformity of data to normal distribution was evaluated with the Shapiro-Wilk test and homogeneity of variance with the Levene test. When comparing the quantitative data of 2 independent groups, the Independent Samples T test was used together with Bootstrap results, and Mann-Whitney $U$ (Exact) test was used together with Monte Carlo results. When comparing the quantitative data of more than 2 groups, One-Way Anova and Kruskal-Wallis H Tests were used. Dunn's Test, Fisher's Least Significant Difference (LSD) and Games-Howell tests were applied for Post Hoc analyses. To examine the correlations of variables, the Pearson Chi-Square and Fisher Exact tests were applied with the Monte Carlo stimulation technique. Quantitative variables were shown as mean \pm standard deviation (SD) and median range (maximumminimum), and categorical variables as number (n) and percentage (\%) in tables. Variables were analyzed at $95 \%$ confidence level and a value of $\mathrm{p}<0.05$ was accepted as statistically significant.

\section{Results}

Of the total patients, $73.9 \%$ with a benign pulmonary mass and $77.6 \%$ with a malignant pulmonary mass were male. The mean age of patients with a benign mass was $58.43 \pm 13.10$ years, in those with a malignant mass, it was $58.56 \pm 12.03$ years. No significant difference was determined between the patient groups with a benign or malignant pulmonary mass in respect of the $S U V_{\max }$ and $S U V_{\text {mean }}$ ratios of the liver/aorta, spleen/aorta, and bone marrow/aorta (pSUV $_{\max } 0.455,0.894,0.469$, respectively; $\mathrm{pSUV}_{\text {mean }} 0.203,0.651$, 0.553 , respectively). No significant difference was determined between the 2 patient groups in respect of the $S U V_{\text {max }}$ and $S U V_{\text {mean }}$ ratios of the spleen/liver, and bone marrow/liver $\left(\mathrm{pSUV}_{\max } 0.821,0.485\right.$, respectively; $\mathrm{pSUV}$ mean $0.107,0.673$, respectively). The $S U V_{\max }$ ratios of the mass/aorta and mass/liver were significantly different between the groups ( $\mathrm{pSUV}_{\max } 0.003$ and 0.006 , respectively). No significant difference was determined between the groups in respect of leukocyte, thrombocyte, lymphocyte, neutrophil counts, and NLR and PLR (Table 1, Figures 1 and 2).

\begin{tabular}{|l|l|l|l|l|}
\hline & $\begin{array}{l}\text { Benign mass } \\
(\mathbf{n}=\mathbf{4 6})\end{array}$ & $\begin{array}{l}\text { Malignant mass } \\
(\mathbf{n = 8 5 )}\end{array}$ & $\begin{array}{l}\text { Total patients } \\
(\mathbf{n}=\mathbf{1 3 1})\end{array}$ & $\mathbf{p}$ value \\
\hline Gender & $\mathrm{n}(\%)$ & $\mathrm{n}(\%)$ & $\mathrm{n}(\%)$ & \\
\hline Male & $34(73.9)$ & $66(77.6)$ & $100(76.3)$ & 0.67 \\
\hline
\end{tabular}


Citation: Komek H, Altindag S, Can C (2017) Association of PET Scan Parameters of Pulmonary Masses and Reticuloendothelial System with Hematologic Parameters. J Nucl Med Radiat Ther 8: 327. doi:10.4172/2155-9619.1000327

Page 3 of 9

\begin{tabular}{|c|c|c|c|c|}
\hline Female & $12(26.1)$ & $19(22.4)$ & $31(23.7)$ & \\
\hline & Mean \pm SD & Mean \pm SD & Mean \pm SD & \\
\hline Age & $58.43 \pm 13.10$ & $58.56 \pm 12.03$ & $58.52 \pm 12.37$ & 0.964 \\
\hline SUV ratio & Median (Max-Min) & Median (Max-Min) & Median (Max-Min) & \\
\hline SUVmax liver/aorta & $1.33(2.76-0.34)$ & $1.22(2.50-0.67)$ & $1.26(2.76-0.34)$ & 0.455 \\
\hline SUVmean liver/aorta & $1.23(2.43-0.70)$ & $1.19(2.29-0.58)$ & $1.20(2.43-0.58)$ & 0.203 \\
\hline SUVmax spleen/aorta & $1.20(2.74-0.43)$ & $1.19(2.71-0.60)$ & $1.20(2.74-0.43)$ & 0.894 \\
\hline SUVmeanspleen/aorta & $1.20(2.35-0.62)$ & $1.21(2.59-0.59)$ & $1.21(2.59-0.59)$ & 0.651 \\
\hline SUVmax bone marrow/aorta & $1.52(4.42-0.62)$ & $1.52(4.28-0.58)$ & $1.52(4.42-0.58)$ & 0.469 \\
\hline SUVmean bone marrow/aorta & $1.54(4.14-0.58)$ & $1.48(4.22-0.55)$ & $1.51(4.22-0.55)$ & 0.553 \\
\hline SUVmean spleen/liver & $0.94(1.57-0.50)$ & $1.01(2.29-0.56)$ & $0.97(2.29-0.50)$ & 0.107 \\
\hline SUVmax spleen/liver & $0.96(1.57-0.49)$ & $0.97(1.84-0.45)$ & $0.97(1.84-0.45)$ & 0.821 \\
\hline SUVmean bone marrow/liver & $1.21(2.92-0.40)$ & $1.24(3.01-0.49)$ & $1.24(3.01-0.40)$ & 0.673 \\
\hline SUVmax bone marrow/liver & $1.15(4.58-0.45)$ & $1.14(2.82-0.60)$ & $1.14(4.58-0.45)$ & 0.485 \\
\hline SUVmax mass/aorta & $3.30(11.80-0)$ & $5.55(14.88-0.64)$ & $4.82(14.88-0)$ & 0.003 \\
\hline SUVmax mass/liver & $2.72(7.30-0)$ & $4.12(15.38-0.25)$ & $3.67(15.38-0)$ & 0.006 \\
\hline \multicolumn{5}{|l|}{ СВC } \\
\hline Leukocyte & $8.92(19.20-1.36)$ & $9.29(26.03-2.49)$ & $9.00(26.03-1.36)$ & 0.536 \\
\hline Thrombocyte & $257.50(530-84.40)$ & $293.00(668.00-120)$ & $282.00(668.00-84.40)$ & 0.098 \\
\hline Neutrophil & $5.41(17.10-0.30)$ & $6.00(86.40-0.88)$ & $5.61(86.40-0.30)$ & 0.214 \\
\hline Lymphocyte & $1.72(5.03-0.26)$ & $1.73(7.20-0.52)$ & $1.73(7.20-0.26)$ & 0.598 \\
\hline NLR & $2.78(19.88-0.07)$ & $3.27(13.52-0.32)$ & $3.13(19.88-0.07)$ & 0.151 \\
\hline PLR & $138.39(1.091 .43-41.30)$ & $159.09(580.25-52.78)$ & $156.02(1.091 .43-41.30)$ & 0.148 \\
\hline
\end{tabular}

Table 1: Demographic and clinical parameters of patients.

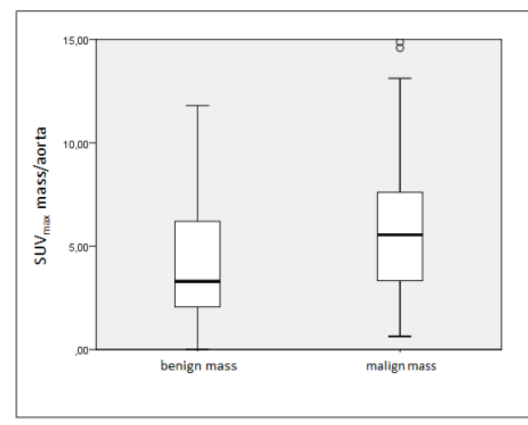

Figure 1: Difference between groups according to $\mathrm{SUV}_{\max }$ ratio of mass/aorta.

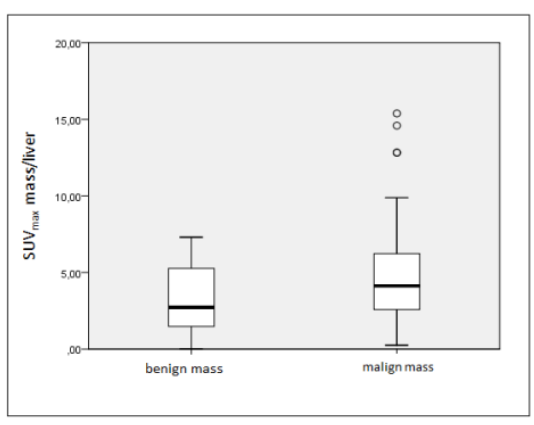

Figure 2: Difference between groups according to SUVmax ratio of mass/liver. 
Citation: Komek H, Altindag S, Can C (2017) Association of PET Scan Parameters of Pulmonary Masses and Reticuloendothelial System with Hematologic Parameters. J Nucl Med Radiat Ther 8: 327. doi:10.4172/2155-9619.1000327

Page 4 of 9

Male gender was determined in $73.9 \%$ of the patients with a benign mass, in $74.5 \%$ of non-squamous cancer cases, and in $81.6 \%$ of squamous cell tumor cases. The mean age of these groups was $58.43 \pm$ 13.10 years, $54.77 \pm 12.05$ years, and $63.26 \pm 10.36$ years, respectively. The mean age was significantly higher in the squamous cell carcinoma group compared to the non-squamous carcinoma group $(\mathrm{p}=0.001)$. There were no significant differences between the groups in respect of $\mathrm{SUV}_{\max }$ and $\mathrm{SUV}_{\text {mean }}$ ratios of liver/aorta, spleen/aorta, bone marrow/ aorta $\left(\mathrm{pSUV}_{\max } 0.621,0.968,0.596\right.$ respectively; $\mathrm{pSUV}_{\text {mean }} 0.328$, $0.595,0.178$, respectively). No significant differences were determined between the groups in respect of the $S U V_{\max }$ and $S U V_{\text {mean }}$ ratios of spleen/liver and bone marrow/liver. A significant difference was determined between patients with a benign mass and squamous cell carcinoma in respect of the $S U_{\text {max }}$ ratios of mass/aorta and mass/liver $(p<0.001$ and $p=0.001$, respectively), and between the non-squamous carcinoma and squamous cell carcinoma patients $(\mathrm{p}=0.049$ and $\mathrm{p}=0.038$, respectively).

These $\mathrm{SUV}_{\max }$ ratios were determined as highest in the squamous cell carcinoma group and lowest in the benign mass group. Although the number of platelets were highest in the squamous cell carcinoma group $(\mathrm{p}=0.034)$, no statistically significant differences were detected between pathological subgroups of patients for leukocyte, neutrophil, and lymphocyte numbers, and NLR and PLR (Table 2).

\begin{tabular}{|c|c|c|c|c|c|}
\hline & \multicolumn{4}{|c|}{ Pathological results } & \multirow[t]{3}{*}{$\mathrm{p}$ value } \\
\hline & Benign mass & Nonsquamous cancer & Squamous cell carcinoma & Total & \\
\hline & $(n=46)$ & $(n=47)$ & $(n=38)$ & $(n=131)$ & \\
\hline Gender & $n(\%)$ & $n(\%)$ & $n(\%)$ & $n(\%)$ & \\
\hline Male & 34 (73.9) & $35(74.5)$ & $31(81.6)$ & $100(76.3)$ & 0.738 \\
\hline \multirow[t]{2}{*}{ Female } & $12(26.1)$ & $12(25.5)$ & $7(18.4)$ & $31(23.7)$ & \\
\hline & Mean \pm SD & Mean \pm SD & Mean \pm SD & Mean \pm SD & \\
\hline Age & $58.43 \pm 13.10$ & $54.77 \pm 12.05$ & $63.26 \pm 10.362$ & $58.52 \pm 12.37$ & 0.006 \\
\hline \multirow[t]{2}{*}{ Thrombocyte } & $271.68 \pm 87.76$ & $287.60 \pm 87.23$ & $327.45 \pm 121.531$ & $293.57 \pm 100.40$ & 0.034 \\
\hline & $\begin{array}{l}\text { Median } \\
\text { (Max-Min) }\end{array}$ & $\begin{array}{l}\text { Median } \\
\text { (Max-Min) }\end{array}$ & $\begin{array}{l}\text { Median } \\
\text { (Max-Min) }\end{array}$ & $\begin{array}{l}\text { Median } \\
\text { (Max-Min) }\end{array}$ & \\
\hline SUVmax liver/aorta & $1.33(2.76-0.34)$ & $1.25(2.50-0.80)$ & $1.21(2.41-0.67)$ & $1.26(2.76-0.34)$ & 0.621 \\
\hline $\begin{array}{l}\text { SUVmean liver/ } \\
\text { aorta }\end{array}$ & $1.23(2.43-0.70)$ & $1.21(1.95-0.64)$ & $1.18(2.29-0.58)$ & $1.20(2.43-0.58)$ & 0.328 \\
\hline $\begin{array}{l}\text { SUVmax spleen/ } \\
\text { aorta }\end{array}$ & $1.20(2.74-0.43)$ & $1.19(2.71-0.63)$ & $1.20(2.56-0.60)$ & $1.20(2.74-0.43)$ & 0.968 \\
\hline $\begin{array}{l}\text { SUVmean spleen/ } \\
\text { aorta }\end{array}$ & $1.20(2.35-0.62)$ & $1.20(2.59-0.59)$ & $1.23(2.40-0.63)$ & $1.21(2.59-0.59)$ & 0.595 \\
\hline $\begin{array}{l}\text { SUVmax bone } \\
\text { marrow/aorta }\end{array}$ & $1.52(4.42-0.62)$ & $1.50(4.04-0.77)$ & $1.54(4.28-0.58)$ & $1.52(4.42-0.58)$ & 0.596 \\
\hline $\begin{array}{l}\text { SUVmean bone } \\
\text { marrow/aorta }\end{array}$ & $1.54(4.14-0.58)$ & $1.32(4.22-0.72)$ & $1.71(3.53-0.55)$ & $1.51(4.22-0.55)$ & 0.178 \\
\hline $\begin{array}{l}\text { SUVmean spleen/ } \\
\text { liver }\end{array}$ & $0.94(1.57-0.50)$ & $0.94(2.29-0.56)$ & $1.06(1.85-0.68)$ & $0.97(2.29-0.50)$ & 0.03 \\
\hline $\begin{array}{l}\text { SUVmax spleen/ } \\
\text { liver }\end{array}$ & $0.96(1.57-0.49)$ & $0.92(1.84-0.45)$ & $0.98(1.77-0.61)$ & $0.97(1.84-0.45)$ & 0.444 \\
\hline $\begin{array}{l}\text { SUVmeanbone } \\
\text { marrow/liver }\end{array}$ & $1.21(2.92-0.40)$ & $1.18(3.01-0.49)$ & $1.41(2.97-0.59)$ & $1.24(3.01-0.40)$ & 0.2 \\
\hline $\begin{array}{l}\text { SUVmax bone } \\
\text { marrow/liver }\end{array}$ & $1.15(4.58-0.45)$ & $1.10(2.69-0.60)$ & $1.17(2.82-0.61)$ & $1.14(4.58-0.45)$ & 0.529 \\
\hline $\begin{array}{l}\text { SUVmax mass/ } \\
\text { aorta }\end{array}$ & $3.30(11.80-0)$ & $4.75(14.59-0.64)$ & $6.78(14.88-1.06)$ & $4.82(14.88-0)$ & $<0.001$ \\
\hline SUVmax mass/liver & $2.72(7.30-0)$ & $3.67(15.38-0.25)$ & $5.73(12.83-0.98)$ & $3.67(15.38-0)$ & $<0.001$ \\
\hline Leukocyte & $8.92(19.20-1.36)$ & $8.68(26.03-4.84)$ & $9.79(22.58-2.49)$ & $9.00(26.03-1.36)$ & 0.663 \\
\hline
\end{tabular}


Citation: Komek H, Altindag S, Can C (2017) Association of PET Scan Parameters of Pulmonary Masses and Reticuloendothelial System with Hematologic Parameters. J Nucl Med Radiat Ther 8: 327. doi:10.4172/2155-9619.1000327

Page 5 of 9

\begin{tabular}{|l|l|l|l|l|l|}
\hline Neutrophil & $5.41(17.10-0.30)$ & $5.60(22.99-0.88)$ & $6.42(86.40-1.65)$ & $5.61(86.40-0.30)$ & 0.436 \\
\hline Lymphocyte & $1.72(5.03-0.26)$ & $1.93(5.57-0.52)$ & $1.64(7.20-0.55)$ & $1.73(7.20-0.26)$ & 0.542 \\
\hline NLR & $2.78(19.88-0.07)$ & $2.93(13.52-0.32)$ & $4.10(12.00-0.87)$ & $3.13(19.88-0.07)$ & 0.155 \\
\hline PLR & $138.39(1.091 .43-41.30)$ & $145.27(580.25-52.78)$ & $202.25(503.57-55.69)$ & $156.02(1.091 .43-41.30)$ & 0.123 \\
\hline \multicolumn{2}{|l|}{ OneWay ANOVA Test- Post Hoc Test: LSD - Games Howell; Kruskal Wallis Test-Post Hoc Test : Dunn's Test-SD.: Standard deviation-Max.: Maximum-Min : Minimum } \\
\hline
\end{tabular}

Table 2: Demographic and clinical parameters of patients according to pathological Results.

Leukocyte numbers were not correlated with the $\mathrm{SUV}_{\max }$ and $\mathrm{SUV}_{\text {mean }}$ ratios of RES organs and mass lesions. The $\mathrm{SUV}_{\text {max }}$ ratios of mass/aorta and mass/liver were positively correlated with neutrophil counts, and no other significant correlations were found between neutrophil counts and SUV ratios. The SUV $\max$ bone marrow/aorta, $\mathrm{SUV}_{\text {mean }}$ bone marrow/aorta, $\mathrm{SUV}_{\text {mean }}$ spleen/liver, $\mathrm{SUV}_{\text {mean }}$ bone marrow/liver, $\mathrm{SUV}_{\max }$ bone marrow/liver, $\mathrm{SUV}_{\max }$ mass/aorta, $\mathrm{SUV}_{\max }$ mass/liver ratios were positively correlated with thrombocyte counts. A significant negative correlation was determined between thrombocyte counts and the $\mathrm{SUV}_{\text {mean }}$ ratio of liver/aorta. Significant negative correlations were determined between lymphocyte counts, and the $\mathrm{SUV}_{\text {mean }}$ ratios of spleen/aorta and spleen/liver. NLR was significantly correlated with the $\mathrm{SUV}_{\max }$ ratios of spleen/aorta, spleen/liver, mass/ aorta, mass/liver, and the $\mathrm{SUV}_{\text {mean }}$ ratios of spleen/aorta, bone marrow/aorta, spleen/liver, bone marrow/liver. PLR was significantly correlated with the $\mathrm{SUV}_{\max }$ ratios of spleen/liver, bone marrow/liver, mass/aorta, mass/liver, and the $\mathrm{SUV}_{\text {mean }}$ ratios of spleen/aorta, bone marrow/aorta, spleen/liver, bone marrow/liver (Table 3).

\begin{tabular}{|c|c|c|c|c|c|c|c|}
\hline & & Leukocyte & Thrombocyte & Neutrophil & Lymphocyte & NLR & PLR \\
\hline \multirow[t]{2}{*}{ SUVmax liver/aorta } & $r$ & 0.078 & -0.113 & 0.003 & 0.043 & -0.041 & -0.093 \\
\hline & $P$ & 0.374 & 0.199 & 0.974 & 0.624 & 0.645 & 0.293 \\
\hline \multirow[t]{2}{*}{ SUVmean liver/aorta } & $r$ & -0.048 & $-0.194^{*}$ & -0.1 & 0.021 & -0.073 & -0.104 \\
\hline & $P$ & 0.587 & 0.026 & 0.255 & 0.813 & 0.404 & 0.238 \\
\hline \multirow[t]{2}{*}{ SUVmax spleen/aorta } & $r$ & 0.097 & 0.071 & 0.138 & -0.103 & $.236^{\star \star}$ & 0.146 \\
\hline & $\mathrm{P}$ & 0.27 & 0.421 & 0.116 & 0.242 & 0.007 & 0.097 \\
\hline \multirow[t]{2}{*}{ SUVmean spleen/aorta } & $r$ & -0.012 & 0.065 & 0.034 & $-0.221^{*}$ & $0.249^{* *}$ & $0.246^{* *}$ \\
\hline & $P$ & 0.893 & 0.459 & 0.701 & 0.011 & 0.004 & 0.005 \\
\hline \multirow{2}{*}{$\begin{array}{l}\text { SUVmax bone marrow/ } \\
\text { aorta }\end{array}$} & $r$ & 0.083 & $0.219^{*}$ & 0.082 & -0.021 & 0.101 & 0.141 \\
\hline & $P$ & 0.347 & 0.012 & 0.35 & 0.809 & 0.253 & 0.107 \\
\hline \multirow{2}{*}{$\begin{array}{l}\text { SUVmean bone marrow/ } \\
\text { aorta }\end{array}$} & r & 0.046 & $0.180^{*}$ & 0.075 & -0.144 & $0.175^{*}$ & $0.219^{*}$ \\
\hline & $\mathrm{P}$ & 0.602 & 0.039 & 0.396 & 0.102 & 0.045 & 0.012 \\
\hline \multirow[t]{2}{*}{ SUVmean spleen/liver } & $r$ & 0.028 & $0.259^{* *}$ & 0.119 & $-0.271^{* *}$ & $0.358^{* *}$ & $0.380^{* *}$ \\
\hline & $P$ & 0.753 & 0.003 & 0.177 & 0.002 & 0 & 0 \\
\hline \multirow[t]{2}{*}{ SUVmax spleen/liver } & $r$ & 0.005 & 0.158 & 0.091 & -0.171 & $0.262^{* *}$ & $0.241^{* *}$ \\
\hline & $P$ & 0.955 & 0.071 & 0.302 & 0.051 & 0.003 & 0.006 \\
\hline \multirow{2}{*}{$\begin{array}{l}\text { SUVmean bone marrow/ } \\
\text { liver }\end{array}$} & $r$ & 0.065 & $0.289^{* *}$ & 0.119 & -0.161 & $0.215^{*}$ & $0.281^{* *}$ \\
\hline & $\mathrm{P}$ & 0.462 & 0.001 & 0.176 & 0.065 & 0.014 & 0.001 \\
\hline \multirow{2}{*}{$\begin{array}{l}\text { SUVmax bone marrow/ } \\
\text { liver }\end{array}$} & r & 0.044 & $0.294^{* *}$ & 0.083 & -0.035 & 0.118 & $0.183^{*}$ \\
\hline & $P$ & 0.615 & 0.001 & 0.344 & 0.692 & 0.18 & 0.036 \\
\hline \multirow[t]{2}{*}{ SUVmax mass/aorta } & $r$ & $0.188^{*}$ & $0.291^{* *}$ & $0.188^{*}$ & -0.099 & $0.243^{* *}$ & $0.224^{*}$ \\
\hline & $\mathrm{P}$ & 0.031 & 0.001 & 0.032 & 0.262 & 0.005 & 0.01 \\
\hline
\end{tabular}




\begin{tabular}{|l|l|l|l|l|l|l|l|}
\hline SUVmax mass/liver & $\mathrm{r}$ & 0.162 & $0.289^{* *}$ & $0.182^{*}$ & -0.109 & $0.240^{* *}$ & $0.230^{* *}$ \\
\cline { 2 - 8 } & $\mathrm{P}$ & 0.065 & 0.001 & 0.037 & 0.215 & 0.006 & 0.008 \\
\hline
\end{tabular}

Table 3: Correlations between hematological parameters and SUV ratios.

\section{Discussion}

The immune system is composed of several mechanisms protecting the body against several kinds of pathogens [6-8]. As a part of the immune system, RES consists of cells located in lymph nodes, spleen, liver, and bone marrow, and has an important place in the fight against pathogens [9-11]. Each part of this system has a unique role in immunity; the liver has a high antigenic load from its blood flow and local immune coping mechanisms, the spleen contributes to both humoral and cellular immunity and bone marrow plays a role in producing immune cells [12-14].

In the current study, no significant difference was determined in respect of the maximum and mean SUV ratios of the liver, spleen, and bone marrow between the patient groups with a benign mass and squamous cell carcinoma and non-squamous cancers. In a study by Bural et al. [15] evaluation was made of 39 subjects evaluated for pulmonary nodules and who showed no evidence of activity on $18 \mathrm{~F}$ FDG PET imaging, and 30 subjects with lung cancer with and without distant metastases detected on 18F-FDG PET imaging. In contrast to the current study, the findings of that study revealed a statistically significant difference in respect of the SUV $V_{\text {mean }}$ values of the RES organs (liver, spleen, bone marrow) in favor of patient group with malignant cancer $(\mathrm{p}<0.05)$. However, in that study, $20 \%$ of the cancer patients were diagnosed as squamous cell carcinoma, while in the current study the ratio was $44 \%$. Thus it may be proposed that differences in distribution of pathological subclasses of lung cancer may lead to discrepancy when comparing SUV results. However, increased $S U V_{\text {mean }}$ in patients with lung cancer, as shown in this study, suggests that as a part of the immune system developing defense against malignancy, RES could present increased activity. The increased activity and phagocytic mechanisms causing increased glucose utilization and uptake lead to increased 18F-FDG uptake. Hence, the increased activity in the

Several studies have investigated whether hematological parameters such as platelets, MPV, PLR, neutrophils, NLR, and leukocytes have any effect on the pathological results of tumoral masses [16]. Recent investigations have suggested that NLR could be a predictor for cardiovascular diseases and cancer [1-3]. NLR as a marker points to subclinical inflammation. In several studies, PLR has also been proposed as a new and simple marker that could be used as an indicator of inflammation accompanied by platelet mediators $[17,18]$. Some studies have also shown that NLR and PLR can be used as markers predicting survival in cancer patients including those with lung cancer [19-22]. Moreover, these markers may be easily obtained in daily practice $[23,24]$. Therefore, in the current study, NLR and PLR values were investigated in pathological subclasses of pulmonary masses to determine whether there was any correlation between NLR and PLR, and SUV ratios. No significant difference was determined between the groups according to NLR and PLR. Nikolić et al. [25] showed significantly higher NLR and PLR values in lung cancer patients $(n=388)$ in comparison with a control group $(n=47)$, but no difference was observed between subgroups of the lung cancer patients [25]. In the current study, NLR was significantly correlated with the $\mathrm{SUV}_{\max }$ ratios of spleen/aorta, spleen/liver, mass/aorta, mass/liver, and with the $S U V_{\text {mean }}$ ratios of spleen/aorta, bone marrow/aorta, spleen/ liver, and bone marrow/liver. PLR was significantly correlated with the $\mathrm{SUV}_{\max }$ ratios of spleen/liver, bone marrow/liver, mass/aorta, mass/ liver, and with the SUV mean ratios of spleen/aorta, bone marrow/aorta, spleen/liver, and bone marrow/liver. Sürücü et al. [26] investigated the association of NLR and PLR with SUV and metabolic tumor volume in a study of 52 esophageal squamous cell carcinoma patients and a control group $(n=52)$. The NLR and PLR values were found to be higher in the patient group compared to the control group, which was consistent with literature. However, in contrast to the current study, it was demonstrated that the $\mathrm{SUV}_{\max }$ of esophageal tumor was not correlated with NLR or PLR. In that study, NLR was found to be correlated with MTV in the patient group, but as previously mentioned, pathological evaluation of metastases was not applied. Nam et al. showed significant correlations between the $S U V_{\max }$ ratio of spleen/liver, and neutrophil and leukocyte counts [27]. Again contrasting with the current study results, in a study of 57 lung cancer patients, Sunnetcioglu et al. [28] reported no correlations of the SUV of the cancer mass with NLR or leukocyte counts. However, similar to the current study, it was shown that in squamous cell cancer patients the $\mathrm{SUV}_{\max }$ values of the tumor mass were higher than in patients with another histopathological diagnosis.

Several kinds of modalities such as MRI, and bone marrow scintigraphy with technetium $99 \mathrm{~m}$, have been used to image bone marrow [29]. However, PET imaging provides both structural and functional knowledge about bone marrow both in benign and malignant conditions [30]. Although there is generally moderate $18 \mathrm{~F}$ FDG uptake by bone marrow in normal individuals, some investigations have shown high uptake by normal individuals on PET imaging. Whether these changes determined on PET scans are important remains unknown as there has been insufficient research to determine which levels of 18F-FDG uptake of bone marrow can be considered abnormally increased. Some studies have suggested a range of 1.3-1.6, using SUV [31,32]. However, SUV changes with many factors different from the features of the relevant organ [31-33]. The uptake of FDG by bone marrow may also be changed according to whether the primary tumor is benign or not. For example, the bone marrow FDG uptake of patients with lung cancer has been found to be higher than that of patients with benign pulmonary nodules [15]. Moreover, bone marrow FDG uptake in patients with a malignancy has been determined to be associated with serum cytokine and CRP levels, and some blood parameters [34-36]. These findings suggest that FDG uptake by bone marrow could point to a systemic immune response. Therefore, the discrimination of the physiological uptake in bone marrow or uptake due to other causes is of great importance clinically. Logically, it could be assumed that FDG uptake by marrow could be correlated with hematopoietic activity of bone marrow. In furtherance of this idea, in studies where bone marrow was imaged after 
administration of G-CSF and GM-CSF, increased activity has been demonstrated, probably given by these factors [32,37-39]. As mentioned previously, in the current study, positive significant correlations were determined between the $\mathrm{SUV}_{\max }$ ratios of bone marrow/aorta and thrombocyte count and there were also significant positive correlations between the $\mathrm{SUV}_{\text {mean }}$ ratios of bone marrow/ aorta, and thrombocyte, NLR and PLR. There were positive significant correlations between the $\mathrm{SUV}_{\max }$ ratios of bone marrow/liver, and thrombocyte and PLR, and significant positive correlations between the $S \mathrm{SV}_{\text {mean }}$ ratios of bone marrow/liver, and thrombocyte, NLR and PLR. Murata et al. [40] investigated the correlations of SUV ratios of bone marrow with hematological parameters in a study of 48 patients. In that study, the values of bone marrow SUV in the lower thoracic spine (Th 11-12) and the upper lumbar spine (L1-2) were calculated, and the uptake ratio (UR) was calculated by dividing the SUV of the bone marrow by the SUV of the longitudinal dorsal muscles.

In contrast to the current study, total leukocyte counts and neutrophil counts were correlated with the SUV and uptake ratios, and the uptake ratios of the bone marrow, respectively. Similar to the current study, there were no correlations between lymphocyte counts and SUV ratio. Lee et al. [41] reported similar results according to the association between the $\mathrm{SUV}_{\text {mean }}$ ratio of bone marrow to liver (BLR) and hematological parameters, in a study of 110 non-small cell lung carcinoma (NSCLC) patients who had undergone curative resection. In that study, BLR was similar between the two groups, whether or not there was recurrence and there were significant positive correlations between BLR and some hematological parameters such as PLR, NLR and total leukocyte counts ( $\mathrm{p}=0.001, \mathrm{p}<0.001, \mathrm{p}=0.03$, respectively). In the same study, only cancer patients curable with resection had been enrolled to exclude the effect of tumor FDG uptake on bone marrow FDG uptake. Again, Lee et al. [41] showed significant positive correlations of BLR with leukocyte numbers but no correlations with NLR or PLR. These findings suggested that bone marrow could indicate that systemic immunity developed as a defense mechanism against primary tumor. As patients were analyzed retrospectively in the current study, predictors for mortality were not investigated. In contrast to the current study, Prévost et al. [42] showed that BLR was a prognostic factor in non-small cell lung carcinoma, in a study of 120 patients.

The results of the current study showed that $\mathrm{SUV}_{\max }$ ratios were determined as highest in the squamous cell carcinoma group and lowest in the benign mass group, but the data were not analyzed to obtain a threshold value of SUV. Several studies have investigated whether the SUV value of pulmonary mass has any role in predicting the mass as benign or malignant [43]. Bryant et al. [44] reported that the higher the SUVmax value, the higher the probability that the pulmonary mass would be malignant. However, in the same study, it was shown that malignancy was found in $24 \%$ of pulmonary nodules with SUV $V_{\max }$ between 0 and 2.5. Huang et al. [45] showed significantly increased $S \mathrm{UV}_{\max }$ values in malignant pulmonary lesions compared to benign lesions. Several $S_{U V}$ max values have been proposed as a threshold for this discrimination. Some studies have accepted 2.5 as the $S_{U V} V_{\max }$ threshold [46-49], although Yi et al. [50] considered masses with a $\mathrm{SUV}_{\max }>3.5$ as malignant. Nguyen stated that a common threshold value for different sites was not feasible, but also reported SUVmax threshold $>3.6$ as highly sensitive and specific for pulmonary nodules [51]. Besides these findings, in some studies, it has been shown that quantitative analysis by PET scan did not improve accuracy [52-54]. Lobrano et al. [55] investigated the effect of SUV of pulmonary mass in differentiating whether the masses were benign or malignant. A total of 73 patients with both PET images and reports and corresponding biopsy results were included in the study. Pulmonary malignancies were determined in $75 \%$, and benign diagnoses in $25 \%$ according to the biopsy results. In that study, SUV was not determined to be a useful predictor in discriminating malignant lesions from benign masses. 18F-FDG uptake in mediastinal or hilar lymph nodes was an important predictor for the pulmonary lesion to be malignant $(\mathrm{p}=0.024)$.

\section{Conclusion}

The results of this study demonstrated that SUV ratios of RES organs in FDG-PET imaging were greater in patients with lung cancer in comparison to healthy subjects, and this effect may have resulted from the development of immune defense against cancer. Further studies are required on this subject.

\section{References}

1. Wang J, Jia Y, Wang N, Zhang X, Tan B, et al. (2014) The clinical significance of tumor-infiltrating neutrophils and neutrophil-to- CD8+ lymphocyte ratio in patients with resectable esophageal squamous cell carcinoma. J Transl Med 12:7.

2. Xue P, Kanai M, Mori Y, Nishimura T, Uza N, et al. (2014) Neutrophil-tolymphocyte ratio for predicting palliative chemotherapy outcomes in advanced pancreatic cancer patients. Cancer Med 3: 406-415.

3. Wang X, Zhang G, Jiang X, Zhu H, Lu Z, et al. (2014) Neutrophil to lymphocyte ratio in relation to risk of all-cause mortality and cardiovascular events among patients undergoing angiography or cardiac revascularization: a meta-analysis of observational studies. Atherosclerosis 234: 206-213.

4. Vansteenkiste J, Fischer BM, Dooms C, Mortensen J (2004) Positron emission tomography in prognostic and therapeutic assessment of lung cancer: systematic review. Lancet Oncol 5: 53-40.

5. de Geus-Oei LF, van Krieken JH, Aliredjo RP, Krabbe PF, Frielink C, et al. (2007) Biological correlates of FDG uptake in non-small cell lung cancer. Lung Cancer 55: 79-87.

6. Parkin J, Cohen B (2001) An overview of the immune system. Lancet 357: 1777-1789.

7. Delves PJ, Roitt IM (2000) The immune system. First of two parts. N Engl J Med 343: 37-49.

8. Delves PJ, Roitt IM (2000) The immune system. Second of two parts. N Engl J Med 343: 108-117.

9. Stossel TP (1974) Phagocytosis (first of three parts). N Engl J Med 290: 717-723.

10. Stossel TP (1974) Phagocytosis (third of three parts). N Engl J Med 290: 833-839.

11. Mc Cuskey PA, Kan Z, Wallace S (1994) An electron microscopy study of Kupffer cells in livers of mice having Friend erythroleukemia hepatic metastases. Clin Exp Metastasis 12: 416-426.

12. Doherty DG, O'Farrelly C (2000) Innate and adaptive lymphoid cells in the human liver. Immunol Rev 174: 5-20.

13. Kraal G (1992) Cells in the marginal zone of the spleen. Int Rev Cytol 132: 31-74.

14. Lasser A (1983) The mononuclear phagocytic system: a review. Hum Pathol 14: 108-126.

15. Bural GG, Torigian DA, Chen W, Houseni M, Basu S, et al. (2010) Increased 18F-FDG uptake within the reticuloendothelial system in patients with active lung cancer on PET imaging may indicate activation of the systemic immune response. Hell J Nucl Med 13: 23-25.

16. Templeton AJ, McNamara MG, Seruga B, Vera-Badillo FE, Aneja P, et al. (2014) Prognostic role of neutrophil-to-lymphocyte ratio in solid tumors: a systematic review and metaanalysis. J Natl Cancer Inst 106: dju124. 
17. Balta S, Demirkol S, Kucuk U (2013) The platelet lymphocyte ratio may be useful inflammatory indicator in clinical practice. Hemodial Int 17: 668-669.

18. Akkaya E, Gul M, Ugur M (2014) Platelet to lymphocyte ratio: a simple and valuable prognostic marker for acute coronary syndrome. Int $\mathrm{J}$ Cardiol 177: 597-598.

19. Peng B, Wang YH, Liu YM, Ma LX (2015) Prognostic significance of the neutrophil to lymphocyte ratio in patients with non-small cell lung cancer: a systemic review and meta-analysis. Int J Clin Exp Med 8: 3098-3106.

20. Gu XB, Tian T, Tian XJ, Zhang XJ (2015) Prognostic significance of neutrophil-to-lymphocyte ratio in non-small cell lung cancer: a metaanalysis. Sci Rep 5: 12493.

21. Zhang H, Zhang L, Zhu K, Shi B, Yin Y, et al. (2015) Prognostic significance of combination of preoperative platelet count and neutrophil-lymphocyte ratio (COP-NLR) in patients with nonsmall cell lung cancer: based on a large cohort study. PLoS ONE 10: e0126496.

22. Unal D, Eroglu C, Kurtul N, Oguz A, Tasdemir A (2013) Are neutrophil/ lymphocyte and platelet/lymphocyte rates in patients with nonsmall cell lung cancer associated with treatment response and prognosis? Asian Pac J Cancer Prev 14: 5237-5242.

23. Kacan T, Babacan NA, Seker M, Yucel B, Bahceci A, et al. (2014) Could the neutrophil to lymphocyte ratio be a poor prognostic factor for nonsmall cell lung cancers? Asian Pac J Cancer Prev 15: 2089-2094.

24. Tomita M, Shimizu T, Ayabe T, Yonei A, Onitsuka T (2011) Preoperative neutrophil to lymphocyte ratio as a prognostic predictor after curative resection for non-small cell lung cancer. Anticancer Res 31: 2995-2998.

25. Nikolic I, Kukulj S, Samarzija M, Jelec V, Zarak M, et al. (2016) Neutrophil-to-lymphocyte and platelet-to-lymphocyte ratio help identify patients with lung cancer, but do not differentiate between lung cancer subtypes. Croat Med J 57: 287-292.

26. Suruku E, Demir Y, Sengoz T (2015) The correlation between the metabolic tumor volume and hematological parameters in patients with esophageal cancer. Ann Nucl Med 29: 906-910.

27. Nam HY, Kim SJ, Kim IJ, Kim BS, Pak K, et al. (2010) The clinical implication and prediction of diffuse splenic FDG uptake during cancer surveillance. Clin Nucl Med 35: 759-763.

28. Sunnetcioglu A, Arisoy A, Demir Y, Ekin S, Dogan E (2015) Associations between the standardized uptake value of $18 \mathrm{~F}$-FDG PET/CT and demographic, clinical, pathological, radiological factors in lung cancer. Int J Clin Exp Med 8:15794-15800.

29. Vande Berg BC, Malghem J, Lecouvet FE, Maldague B (1998) Magnetic resonance imaging of the normal bone marrow. Skeletal Radiol 27: 471-483.

30. Blebea JS, Houseni M, Torigian DA, Fan C, Mavi A, et al. (2007) Structural and functional imaging of normal bone marrow and evaluation of its age-related changes. Semin Nucl Med 37: 185-194.

31. Ramos CD, Erdi YE, Gonen M, Riedel E, Yeung HW, et al (2001) FDGPET standardized uptake values in normal anatomical structures using iterative reconstruction segmented attenuation correction and filtered back-projection. Eur J Nucl Med 28: 155-164.

32. Sugawara Y, Fisher SJ, Zasadny KR, Kison PV, Baker LH, et al. (1998) Preclinical and clinical studies of bone marrow uptake of fluorine-1fluorodeoxyglucose with or without granulocyte colony-stimulating factor during chemotherapy. J Clin Oncol 16: 173-180.

33. Thie JA (2004) Understanding the standardized uptake value, its methods, and implications for usage. J Nucl Med 45: 1431-1434.

34. Van de Wiele C, VandeVyver F, Debruyne C, Philippé J, van Meerbeeck JP (2008) FDG uptake by the bone marrow in NSCLC patients is related to TGF-beta but not to VEGF or G-CSF serum levels. Eur J Nucl Med Mol Imaging 35: 519-522.

35. Inoue K, Goto R, Okada K, Kinomura S, Fukuda H (2009) A bone marrow F-18 FDG uptake exceeding the liver uptake may indicate bone marrow hyperactivity. Ann Nucl Med 23: 643-649.
36. Núñez R, Rini JN, Tronco GG, Tomas MB, Nichols K, et al. (2005) Correlation of hematologic parameters with bone marrow and spleen uptake in FDG PET. Rev Esp Med Nucl 24: 107-112.

37. Yao WJ, Hoh CK, Hawkins RA, Glaspy JA, Weil JA, et al (1995) Quantitative PET imaging of bone marrow glucose metabolic response to hematopoietic cytokines. J Nucl Med 36:794-799.

38. Knopp MV, Bischoff H, Rimac A, Oberdorfer F, van Kaick G (1996) Bone marrow uptake of fluorine-18-fluorodeoxyglucose following treatment with hematopoietic growth factors: initial evaluation. Nucl Med Biol 23: 845-849.

39. Hollinger EF, Alibazoglu H, Ali A, Green A, Lamonica G (1998) Hematopoietic cytokine-mediated FDG uptake simulates the appearance of diffuse metastatic disease on whole-body PET imaging. Clin Nucl Med 23: 93-98.

40. Murata Y, Kubota K, Yukihiro M, Ito K, Watanabe H, et al. (2006) Correlations between 18F-FDG uptake by bone marrow and hematological parameters: measurements by PET/CT. Nucl Med Biol 33: 999-1004.

41. Lee JW, Na JO, Kang DY, Lee SY, Lee SM (2016) Prognostic Significance of FDG Uptake of Bone Marrow on PET/CT in Patients With Non-SmallCell Lung Cancer After Curative Surgical Resection. Clin Lung Cancer pii S1525-7304(16)30180-2.

42. Prévost S, Boucher L, Larivée P, Boileau R, Bénard F (2006) Bone marrow hypermetabolism on 18F-FDG PET as a survival prognostic factor in non-small cell lung cancer. J Nucl Med 47: 559-565.

43. Sim YT, Poon FW (2013) Imaging of solitary pulmonary nodule-a clinical review. Quant Imaging Med Surg 3: 316-326.

44. Bryant AS, Cerfolio RJ (2006) The maximum standardized uptake values on integrated FDG-PET/CT is useful in differentiating benign from malignant pulmonary nodules. Ann Thorac Surg 82: 1016-1020.

45. Huang YE, Pu YL, Huang YJ, Chen CF, Pu QH, et al. (2010) The utility of the nonattenuation corrected 18F-FDG PET images in the characterization of solitary pulmonary lesions. Nucl Med Commun 31: 945-951.

46. Al-Sugair A, Coleman RE (1998) Applications of PET in lung cancer. Semin Nucl Med 28: 303-319.

47. Lowe VJ, Fletcher JW, Gobar L, Lawson M, Kirchner P, et al. (1998) Prospective investigation of positron emission tomography in lung nodules. J Clin Oncol 16: 1075-1084.

48. Hashimoto Y, Tsujikawa T, Kondo C, Maki M, Momose M, et al. (2006) Accuracy of PET for diagnosis of solid pulmonary lesions with 18F-FDG uptake below the standardized uptake value of 2.5. J Nucl Med 47: 426-431.

49. Hain SF, Curran KM, Beggs AD, Fogelman I, O'Doherty MJ, et al. (2001) FDG-PET as a "metabolic biopsy" tool in thoracic lesions with indeterminate biopsy. Eur J Nucl Med 28: 1336-1340.

50. Yi CA, Lee KS, Kim BT, Choi JY, Kwon OJ, et al. (2006) Tissue characterization of solitary pulmonary nodule: comparative study between helical dynamic CT and integrated PET/CT. J Nucl Med 47: 443-50.

51. Nguyen NC, Kaushik A, Wolverson MK, Osman MM (2011) Is there a common SUV threshold in oncological FDG PET/CT, at least for some common indications? A retrospective study. Acta Oncol 50: 670-677.

52. Kim SK, Allen-Auerbach M, Goldin J, Fueger BJ, Dahlbom M, et al. (2007) Accuracy of PET/CT in characterization of solitary pulmonary lesions. J Nucl Med 48: 214-220.

53. Kwee TC, Cheng G, Lam MG, Basu S, Alavi A (2013) SUVmax of 2.5 should not be embraced as a magic threshold for separating benign from malignant lesions. Eur J Nucl Med Mol Imaging 40: 1475-1477.

54. Sim YT, Goh YG, Dempsey MF, Han S, Poon FW (2013) PET-CT evaluation of solitary pulmonary nodules: correlation with maximum standardized uptake value and pathology. Lung 191: 625-632.

55. Lobrano MB, Hayman E, Dekelbaum M, Campeau R (2005) Biopsy findings in PET/CT-positive lung lesions in a community hospital. J La State Med Soc 157: 319-324. 